\title{
Urbanisation and coronary heart disease mortality among African Americans in the US South
}

\author{
Elizabeth Barnett, David Strogatz, Donna Armstrong, Steve Wing
}

\begin{abstract}
Study objective - Despite significant declines since the late $1960 \mathrm{~s}$, coronary mortality remains the leading cause of death for African Americans. African Americans in the US South suffer higher rates of cardiovascular disease than African Americans in other regions; yet the mortality experiences of rural-dwelling African Americans, most of whom live in the South, have not been described in detail. This study examined urban-rural differentials in coronary mortality trends among African Americans for the period 1968-86. Setting - The United States South, comprising 16 states and the District of Columbia.
\end{abstract}

Study Population - African American men and women aged 35-74 years.

Design - Analysis of urban-rural differentials in temporal trends in coronary mortality for a 19 year study period. All counties in the US South were grouped into five categories: greater metropolitan, lesser metropolitan, adjacent to metropolitan, semirural, and isolated rural. Annual age adjusted mortality rates were calculated for each urban status group. In 1968, observed excesses in coronary mortality were $29 \%$ for men and $45 \%$ for women, compared with isolated rural areas. Metropolitan areas experienced greater declines in mortality than rural areas, so by 1986 the urban-rural differentials in coronary mortality were $3 \%$ for men and $11 \%$ for women.

Conclusions - Harsh living conditions in rural areas of the South precluded important coronary risk factors and contributed to lower mortality rates compared with urban areas during the 1960 s. The dramatic transformation from an agriculturally based economy to manufacturing and services employment over the course of the study period contributed to improved living conditions which promoted coronary mortality declines in all areas of the South; however, the most favourable economic and mortality trends occurred in metropolitan areas.

( $(\mathcal{E}$ Epidemiol Community Health 1996;50:252-257)

Coronary heart disease remains the leading cause of death among African Americans, ${ }^{1}$ who suffer a disproportionate burden of premature deaths compared with European Americans. ${ }^{2}$ Trends in coronary mortality in the United States have changed remarkably over the course of the 20th century. Until the mid 1960 s, coronary mortality among African Americans steadily increased for the nation as a whole. After the late 1960 s, a downward trend began that continued through 1986 at the national level. ${ }^{1}$

Favourable national level trends may, however, obscure less favourable trends in certain regions and localities. The relative importance of known risk factors in the aetiology of coronary heart disease may vary across different populations and localities. ${ }^{3}$ Studies which disaggregate national trends to describe and analyse geographic variation are crucial both for aetiological inquiry and for planning public health interventions.

In the 19th and early 20th centuries, total mortality among African Americans was significantly higher in urban areas than in rural areas, due to crowded and inadequate housing, poor sanitation systems, and poverty. ${ }^{4}$ There is evidence that as the overall standard of living of African Americans improved through the mid-20th century, the urban-rural gap in mortality narrowed. ${ }^{4}$ However, despite the reduction in geographic inequality for total mortality, an increase in geographic inequality for coronary mortality among African Americans was observed for the period 1962-82.

Urban areas in the United States differ from rural areas both economically and culturally, ${ }^{6-8}$ and various aspects of the social environments of both urban and rural areas are expected to influence coronary heart disease among African Americans, but not necessarily in a consistent manner. Urban areas are characterised by greater economic development and higher levels of community resources, which have been shown to be related to lower levels of coronary heart disease mortality among European Americans. ${ }^{910}$ At the same time, family and community organisation within the cultural milieu of rural areas has been shown to have important health benefits, despite lower economic resources. ${ }^{11-13}$ In addition, the transition from a rural to an urban way of life has been shown to have negative health effects, leading to increased coronary heart disease among European Americans in the US South. ${ }^{1415}$

In this study, we examined the association between urban status of counties and trends in coronary heart disease mortality among African American men and women living in the US South during the years 1968-86. Few studies of geographic variation in coronary mortality among African Americans have been done. ${ }^{16}{ }^{17}$ 
An important strength of this study was our examination of coronary mortality among African Americans living in remote rural areas, mortality rates for this group have not previously been reported.

We focussed on the South for several reasons. African Americans in the South suffer greater cardiovascular disease mortality than African Americans in other regions. ${ }^{18}$ In addition, over $50 \%$ of all African Americans and over $90 \%$ of rural African Americans lived in the South during the study period. Finally, communities in the South share a common history and pattern of population distribution and economic development. From the 1960 s to the 1980 s there was a dramatic transformation in the rural South from agriculturally based local economies to manufacturing based economies. ${ }^{619-21}$ The proportion of African Americans living in rural areas also declined during this time period. We will discuss the potential impact of economic and cultural change in Southern communities on coronary risk factors and mortality for African Americans.

\section{Methods}

The study population consisted of African American men and women aged 35-74 years living in the United States South during the years 1968-86. The South, as defined by the US census Bureau includes 16 states and the District of Columbia. Age and gender specific population totals for each county in each study year were drawn from Census Bureau intercensal population estimates.

Deaths from coronary heart disease were counted, based on the underlying cause of death listed on the death certificate. Since the International Classification of Disease (ICD) ${ }^{22} 23$ was revised midway through the study period, we attempted to use cause of death codes that would provide good comparability between the 8th (1968-1978) and 9th (1979-) ICD revisions. Based on previous research, ${ }^{2425}$ the following codes were chosen: for 1968-78, codes 410-413 (ischaemic heart disease) were used, and for 1978-86, codes 410-414 (ischaemic heart disease), 402 (hypertensive heart disease), and $429 \cdot 2$ (cardiovascular disease unspecified) were used. Death certificate data were obtained from the National Center for Health Statistics.

The classification of the urban status of counties was based on a scheme developed by the Information Sciences Research Institute of the National Center for Health Statistics. ${ }^{26}$ This scheme assigned each county to one of five urbanisation categories based on metropolitan status, population size of the county, and its relative proximity to, or isolation from, major metropolitan areas. The assignment of counties to urban status categories was based on 1980 census data, and the relative urban status of counties was assumed to be constant throughout the study period.

The greater metropolitan group consisted of counties within Standard Metropolitan Statistical Areas (SMSAs) with a total population of one million or more. Lesser metropolitan counties were counties within SMSAs with total population less than one million. The adjacent group was composed of all non-metropolitan counties which were adjacent to metropolitan counties and had easy access to the central city of the metropolitan area. Semi-rural counties were non-metropolitan, not adjacent and had an urban population of at least 2500 , and isolated rural counties were not adjacent to metropolitan areas and had an urban population less than 2500. An urban status code was assigned to each of the 1391 counties in the South.

Data on unemployment, median family income and white collar employment were obtained from the US census for each county, and population weighted averages were computed to provide summary measures for each of the five urban status groups. Data on the industrial sector of African American workers were not available on standard Census Bureau computer tapes for counties in 1960 and 1970. We used published census reports to obtain industrial sector for African American workers (aged 16 and older) in the South for urban and rural areas. ${ }^{27-29}$ The rural population was defined by residence outside of a place with a population of 2500 or more. The urban-rural dichotomy used by the Census Bureau was not based on county of residence, but rather on place of residence within counties, and so was not directly comparable with the five levels of urbanization used in our mortality analyses.

\section{ANALYSIS}

Mortality analyses were conducted separately for men and women. Coronary heart disease deaths and population counts for five year age groups from 35 to 74 were summed within urban groups. Direct age adjusted rates were calculated for each urban status category for the years 1968-86. The 1970 US population was used as the standard population for age adjustment. For each study year, the mortality rate for a particular urban status group represented an average of the coronary mortality experience of all the counties in that group. Graphs of coronary mortality trends from 1968-86 for each of the urban status groups were created. Small populations in rural areas led to some temporal instability in the rates; therefore we graphed three-year running average rates for all urban status groups. For 1968, the average of the rates for 1968 and 1969 was graphed and for 1986 the average of the rates for 1985 and 1986 was graphed. Total declines in coronary mortality were calculated using the observed age adjusted rates for 1968 and 1986.

\section{Results}

The majority of African Americans aged 35-74 (63.9\%) lived in metropolitan counties in 1968. By 1986 the proportion of African Americans in the study population who lived in semirural or isolated rural areas had dropped from $18.3 \%$ to $15.0 \%$, while the proportion living in metro- 
Table 1 County urbanisation and local economic resources in the United States South

\begin{tabular}{lcccc}
\hline & $\begin{array}{l}\text { Greater } \\
\text { metropolitan }\end{array}$ & $\begin{array}{l}\text { Lesser } \\
\text { metropolitan }\end{array}$ & $\begin{array}{l}\text { Adjacent to } \\
\text { metropolitan }\end{array}$ & Semirural \\
rural
\end{tabular}

politan areas had increased to $69 \cdot 3 \%$ (table 1 ). Median family incomes in 1960 for all races were more than twice as high in greater metropolitan areas as an isolated rural areas (table 1). Although family incomes increased from 1960 to 1980 in all areas, inequalities between metropolitan areas and rural areas were not reduced. African American median family income for the South as a whole was $54 \%$ of white median family income in $1967,,^{30}$ and $56 \%$ of white median family income in $1980 .^{31}$ Similar associations with county urbanisation were observed for rates of white collar employment and unemployment. In 1960, $46.6 \%$ of the labour force in greater metropolitan areas were employed in white collar occupations, compared with only $23.2 \%$ of workers in isolated rural areas. White collar employment increased in all areas, with the greatest increases in metropolitan areas. Unemployment rates in 1960 were lowest in metropolitan areas, and highest in semirural and isolated rural areas. From 1960 to 1980 , greater metropolitan areas experienced no net increase in the rate of unemployment, while in isolated

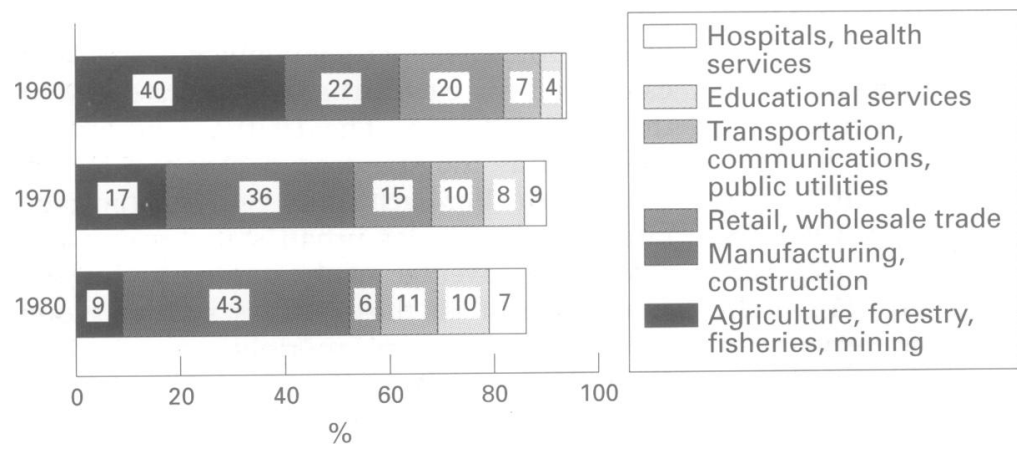

Figure 1 Leading industries of African American workers in the rural US South, 1960-80.

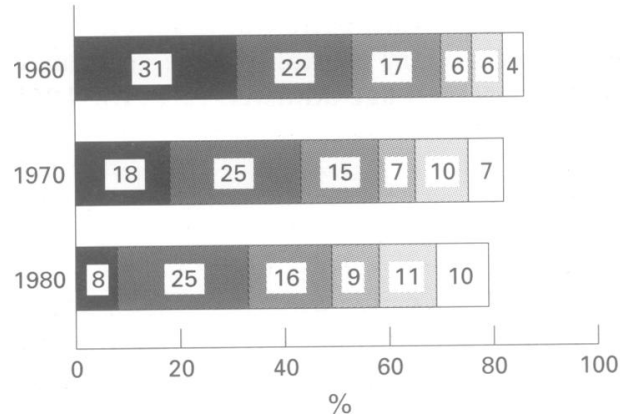

\begin{tabular}{|l|}
\hline$\square$ Hospitals, health \\
services \\
$\square$ Educational services \\
Transportation, \\
communications, \\
public utilities \\
Retail, wholesale trade \\
Manufacturing, \\
construction \\
Private households, \\
personal services \\
\hline
\end{tabular}

Figure 2 Leading industries of African American workers in the urban US South, $1960-80$. rural areas unemployment increased $37 \%$, from $6 \cdot 4 \%$ to $8 \cdot 7 \%$.

From 1960 to 1980 , the total farm population in the South declined $75 \%$, while the African American farm population for the entire United States declined $87 \%$ (both figures unadjusted for population growth). ${ }^{31}$ The transformation of agriculturally based Southern rural economies resulted in changes over time in the industries in which African Americans found employment. In 1960, 40\% of all African American workers living in rural areas of the South were employed in agriculture, forestry, fisheries, or mining (fig 1). Private households and personal services accounted for another $20 \%$ of rural employed African Americans. Although slavery had ended almost 100 years previously, in 1960 most rural African Americans were still employed in agriculture or private households. By 1980 the industrial distribution of the rural African American labour force had dramatically changed. Only $9 \%$ of rural African Americans worked in agriculture or other extractive industries, and only $6 \%$ worked in private households or personal services. Over $43 \%$ of employed African Americans now worked in manufacturing, compared with $22 \%$ in 1960 . Retail and wholesale trade and hospitals and health services also increased their share of Southern rural labour markets between 1960 and 1980 .

In urban areas of the South the leading industries of African American workers also shifted from 1960 to 1980 , although not as dramatically as in rural areas (fig 2). Private household and personal service workers accounted for $31 \%$ of employed urban African Americans in 1960, but accounted for only $8 \%$ in 1980. Employment in most other industries increased moderately from 1960 to 1980 . Service sector employment predominated in 1980 , with only $25 \%$ of urban African Americans working in manufacturing or construction.

The relationship between urban status and levels of coronary mortality was the same for African American women and men (figs 3 and 4). At the beginning of the study period the highest coronary mortality was found in greater metropolitan areas, followed by lesser metropolitan areas. Counties adjacent to metropolitan areas and semirural areas had similar rates, and the lowest coronary mortality rates occurred in isolated rural areas. For African American men living in greater metropolitan areas in 1968 , there was a $29 \%$ excess in coronary heart disease mortality compared with isolated rural areas, while for African American 


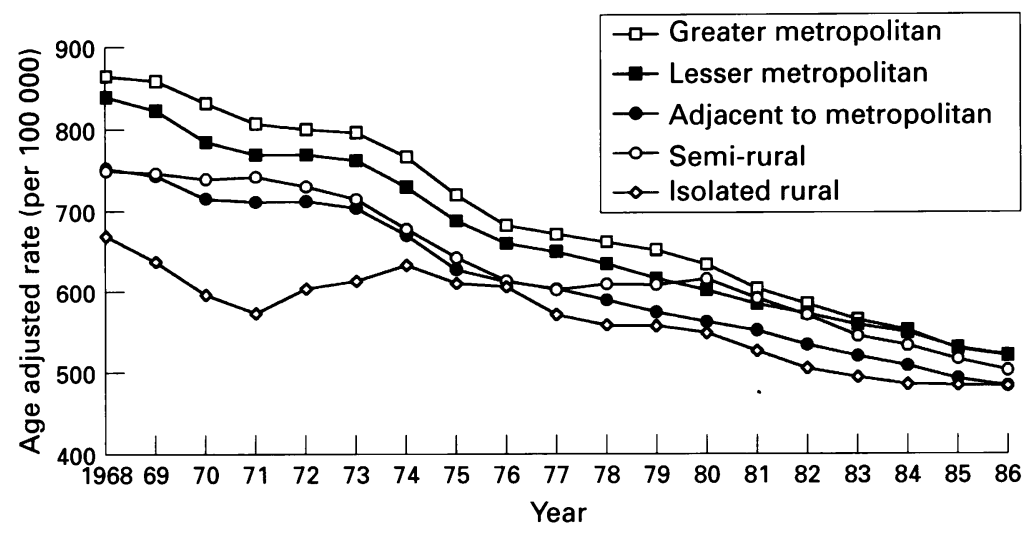

Figure 3 Connary heart disease mortality among African American men aged 35-74 years in the US South.

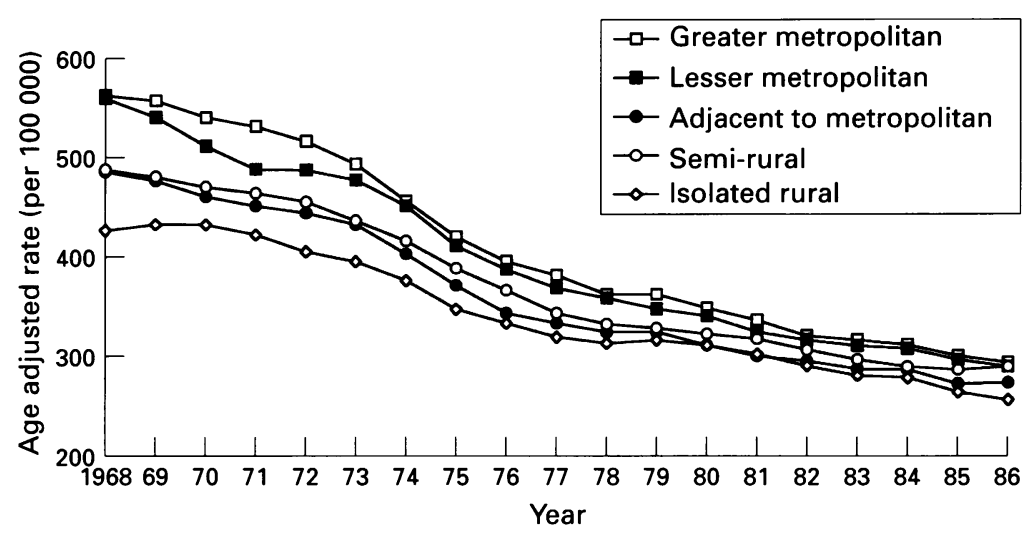

Figure 4 Coronary heart disease mortality among African American women aged 35-74 years in the US South.

women there was a $45 \%$ excess. Over the course of the study period, coronary mortality trends for the five urban status groups converged for both women and men, so that in 1986 the excess in CHD mortality for greater metropolitan areas compared with isolated rural areas was only $3 \%$ for men and $11 \%$ for women.

Total declines in coronary mortality over the 19-year study period were substantial for both African American women and men (table 2). Although African Americans in isolated rural areas experienced the lowest rates of coronary mortality, the greatest declines in mortality occurred in greater metropolitan areas of the South. There was a clear urban-rural gradient in both total percentage declines and total absolute declines in coronary mortality, with isolated rural areas experiencing the smallest declines. In all urban status groups, African American women experienced greater relative but smaller absolute declines in coronary mortality than African American men.

Table 2 Total declines in coronary mortality from 1968-86 for African Americans aged 35-74 years in the United States South

\begin{tabular}{llllll}
\hline & $\begin{array}{l}\text { Greater } \\
\text { metropolitan }\end{array}$ & $\begin{array}{l}\text { Lesser } \\
\text { metropolitan }\end{array}$ & $\begin{array}{l}\text { Adjacent } \\
\text { metropolitan }\end{array}$ & $\begin{array}{l}\text { Semi- } \\
\text { rural }\end{array}$ & $\begin{array}{l}\text { Isolated } \\
\text { rural }\end{array}$ \\
\hline \% decline & & & & & \\
$\quad \begin{array}{l}\text { Men } \\
\text { Women }\end{array}$ & $41 \cdot 3$ & $41 \cdot 8$ & $39 \cdot 3$ & $36 \cdot 1$ & $26 \cdot 3$ \\
$\begin{array}{l}\text { Absolute decline } \\
\text { (deaths/100 000) }\end{array}$ & $50 \cdot 3$ & $49 \cdot 7$ & $46 \cdot 0$ & $40 \cdot 8$ & $34 \cdot 7$ \\
$\quad \begin{array}{l}\text { Men } \\
\text { Women }\end{array}$ & 359 & 362 & 305 & & \\
\hline
\end{tabular}

\section{Discussion}

Historically, coronary heart disease has been positively associated with industrialisation, societal wealth, and higher social class. ${ }^{32}$ The United States and western Europe continue to experience dramatically higher rates than less industrialised and underdeveloped nations. However, the onset of decline in coronary mortality was accompanied by a change in the character of coronary heart disease from a disease of the affluent to a disease increasingly of the disadvantaged and poor. ${ }^{33}$ This transformation reflects overall improvements in standards of living which led to changes in the material conditions of the poor and working class. In the first half of the 20th century, many African Americans lived in conditions which more closely approximated those of populations in underdeveloped areas than they resembled the material conditions of most European Americans. ${ }^{44}$ This was especially true in the rural South, where poverty and a life of hard physical labour precluded important risk factors for coronary heart disease - that is, a sedentary lifestyle and a diet rich in meat and fat. Baseline data from 1960 collected for the Charleston heart study and the Evans County, Georgia heart study showed that rural African Americans had lower mean cholesterol concentrations than urban African Americans, and rural African American women were much less likely to smoke cigarettes than urban African American women. ${ }^{35-38} \mathrm{An}$ analysis of data from the national health and nutrition examination surveys I (1971-74) and II (1976-1980) found that the prevalences of hypertension among black men and women aged 45-54 years in the South were higher in metropolitan areas than in non-metropolitan areas during both time periods. ${ }^{39}$

Many rural African American communities were characterised by close-knit social support networks and positive cohesive cultural environments which may have mitigated against the alienation and psychosocial stress which were more common in urban areas. ${ }^{112}$ In addition, because migration patterns both before and during the study period were predominantly from rural areas to urban areas, ${ }^{34}$ African American adults in isolated rural areas had probably spent their entire lives living in the same rural community. Many were primarily employed in agriculture, or may have worked part time on a family farm. The lower coronary mortality rates compared with metropolitan residents observed for this group in 1968 are consistent with the lower prevalences of coronary risk factors discussed above.

In contrast, the African American residents of metropolitan areas in our study were a more heterogeneous group. Some of them may have lived their whole lives in cities, but given the large migration of African Americans from rural to urban areas which began in the 1940 s and continued through the 1960 s, we assume that a significant proportion of these urban residents spent their childhoods in rural areas. The negative health effects of recent urbanisation for working class European Americans in the South have been documented, ${ }^{1114}$ and we suggest that 
similar effects held true for African Americans in the early years of this study. Given the widespread racism with which all African Americans had to contend, the loss of a community based on kinship networks and personally supportive relationships may have been particularly difficult for recent urban migrants. Psychosocial stress is associated both with coronary heart disease and hypertension, an important coronary risk factor. ${ }^{40-43}$

As the overall standard of living for all African Americans improved in the latter half of the 20th century, economic disparities between the wealthy and the poor did not disappear, but qualitative changes in the material conditions of the poor and working class emerged which contributed to the urban-rural convergence in coronary mortality observed in this study. Improvements in food distribution, relatively lower food costs, and the convenience of processed foods contributed to dietary change in the rural South. Rural residents with improved economic resources were able to eat meat and other high fat foods regularly, and were more likely to lack physical fitness as a result of the transition from agricultural to low-level manufacturing and services employment. ${ }^{445}$ Urban African Americans in the South may have benefited more from the gains of the civil rights movement in the 1960 s than rural African Americans, through access to better jobs, housing, health education, medical care, and health promoting activities such as leisure time physical activity and participation in the arts and recreation. ${ }^{44}$

\section{METHODOLOGICAL ISSUES}

A limitation of the population data used in this study was the underenumeration of the African American population by the United States census in 1970 and 1980. Estimates of the extent of underenumeration by the 1970 census are $10 \cdot 1 \%$ for African American males and 5.3\% for African American females for all ages combined. ${ }^{46}$ In the 1980 census there was a $7 \cdot 5 \%$ underenumeration of African American males and a $2 \cdot 1 \%$ undercount of African American females. ${ }^{47}$ Within the age range $35-74$ the degree of underenumeration was not consistent; for example, in 1980 there were large undercounts for African American men 45-54 $(15 \cdot 1 \%)$ and small overcounts for African American men 65-74 (4.3\%).

One effect of the census undercount of African American populations is a probable overestimation of mortality rates, especially for African American men, assuming that deaths were not undercounted and age at death was classified properly. Bias may be present in this study if the extent of mortality rate overestimation varied by the urban status of counties or by year. It has been suggested that population undercounts were greater in metropolitan areas ${ }^{46}$ but there are no data available to address this question. The possibility that the observed relationships between level of coronary heart disease mortality and urban status of counties were the result of biased mortality estimates can not be excluded. However, it should be noted that approximately one-half of the deaths in this study occurred among African Americans aged 65-74, for whom there were actually small census overcounts in 1980 .

A second limitation and potential source of bias in this investigation, involves misclassification of underlying cause of death on death certificates. Numerous studies attempting to assess the validity and reliability of cause of death certification have been done. ${ }^{48}$ Many have shown a lack of agreement between the cause of death on the death certificate, and cause of death determined from other data sources: autopsies, medical records, hospital discharge records. A study comparing underlying cause of death from the death certificate to multiple diagnoses in the hospital record for 9724 deaths in Vermont found $87 \%$ agreement for acute myocardial infarction (ICDA-8 410) but only $65 \%$ agreement for ischaemic heart disease (ICDA-8 412). For all specific causes of death, relative agreement between death certificate coding and hospital discharge records varied dramatically by hospital. ${ }^{49}$ This is indirect evidence that validity of death certificate coding may vary geographically. However, since a broad grouping of ICD codes was used to define CHD in our study, classification should be better than in studies of single ICD codes.

A recent study showed that, nationwide, approximately $3 \%$ of deaths among African Americans aged 35-74 in 1968 were coded to the ICD cause of death category symptoms, signs, and ill-defined conditions. ${ }^{50}$ This proportion declined over time; in $1988,1.7 \%$ of deaths among men and $1.3 \%$ of deaths among women were coded to this category. There is evidence to suggest that many of these deaths may have been sudden coronary deaths among adults with no previous history of heart disease. ${ }^{50}$ To the extent that coronary deaths were misdiagnosed and miscoded on the death certificate, the mortality rates calculated in this study are underestimates. In addition, if the proportion of all deaths among African Americans in the South coded to ill-defined conditions varied by urban status, the potential for bias due to differential misclassification exists in this study. We indirectly evaluated the potential for information bias by calculating all cause mortality rates for each of the urban status groups (data not shown) and found the same urban-rural mortality gradient which we observed for coronary heart disease mortality.

\section{CONCLUSION}

While coronary heart disease mortality has been declining nationwide among African Americans since the late 1960 s, the rate of decline in coronary mortality slowed after $1975 .{ }^{24} \mathrm{We}$ observed a similar deceleration for the South. In a recent study of coronary mortality trends in North Carolina during the 1980s, there was no decline for African American women from 1980 to $1988 .^{51}$ If the current trends continue, a rural excess in coronary mortality for African Americans in the South will emerge. In order to preserve the tremendous improvements in 
coronary mortality which have occurred over the past 25 years, the mechanisms by which economic and cultural resources of communities help prevent coronary heart disease need to be clarified, with the goal of designing interventions and public policy initiatives which will lessen geographic inequalities and improve the public health.

The authors would like to thank Dr Janet Croft for providing risk factor prevalence data from the Evans County and Charleston Heart Studies, and an anonymous reviewer for helpful comments on an earlier draft of this paper. At the time of this comments on an earlier draft of this paper. At the time of this study, Dr Barnett was supported by a graduate fellowship from the National Science Foundation. This study was part of larger project, Community Structure and Cardiovascular Disease Mortality Trends, funded by the National Heart, Lung,
and Blood Institute (grant R01-HL42320, Dr Wing, principal and Blood Institute (grant R01-HL42320, Dr Wing, principal
investigator). An earlier version of this study was presented at investigator). An earlier version of this study was presented at
the 118th Annual Meeting of the American Public Health Association.

1 Gillum RF. Coronary heart disease in black populations: I. Mortality and morbidity. Am Heart 7 1982;104:839-51.

2 Kapantais G, Powell-Griner E. Characteristics of persons dying of diseases of the heart: preliminary data from the 1986 national mortality followback survey. Advance data from vital and health statistics; no 172 . Hyattsville, MD: National Center for Health Statistics, 1989 .

3 Gary R. Madan JH, Kleinman JC. Regional variation in ischemic heart disease incidence. $\mathcal{F}$ Clin Epidemiol 1992 45:149-56.

4 Ewbank DC. History of black mortality and health before 1940. Millbank $Q$ 1987;65:100-28.

5 Wing S, Casper M, Davis W, Hayes C, Riggan W, Tyroler HA. Trends in the geographic inequality of cardiovascular disease mortality in the United States, 1962-1982. Soc Sci Med 1990;30(3):261-6.

6 Falk WW, Lyson TA. High tech, low tech, no tech. Albany: State University of New York Press, 1988.

7 Farley R. The color line and the quality of life in America. New York: Oxford University Press, 1989.

8 Green GP. Finance capital and uneven development. Boulder, Co: Westview Press, 1987.

9 Wing S, Dargent-Molina P, Casper M, Riggan W, Hayes CG Tyroler HA. Changing association between community occupational structure and ischaemic heart disease mortality in the United States. Lancet 1987;ii:1067-70.

10 Wing S, Barnett E, Casper M, Tyroler HA. Geographic and socioeconomic variation in the onset of decline of coronary heart disease mortality in white women. Am 7 Public Health 1992;82(2):204-9.

11 Cassel J, Patrick R, Jenkins D. Epidemiological analysis of the health implications of culture change: a conceptua model. Ann NY Acad Sci 1960;84:938-49.

12 Green V. The black extended family in the United States: some research suggestions. In: Shimkin DB, Shimkin EM, Frate DA. The extended family in black societies. Hague, Frate DA. The extended family in black societies.
Netherlands: Mouton DeGruyter, 1978;379-87.

13 House JS, Landis KR, Umberson D. Social relationships and health. Science 1988;241:540-5.

14 Tyroler HA, Cassel J. Health consequences of culture chang - II: the effect of urbanization on coronary heart disease mortality in rural residents. $\mathcal{F}$ Chronic Dis 1964;17:167 177.

15 Cassel J, Heyden S, Bartel AG, Kaplan BH, Tyroler HA, Cornoni JC, Hames CG. Incidence of coronary heart disease by ethnic group, social class, and sex. Arch Intem Med 1971;128:901-5.

16 Leaverton PE, Feinleib M, Thom T. Coronary heart disease mortality rates in United States blacks, 1968-1978: inmortality rates in United States blacks, 1968-1978:

17 Kleinman JC, DeGruttola VG, Cohen BB, Madans J Regional and urban-suburban differentials in coronary Regional and urban-suburban differentials in coronary
heart disease mortality and risk factor prevalence. $₹$ Chronic heart disease mortalit

18 Manton KG, Patrick CH, Johnson KW. Health differentials between blacks and whites: recent trends in mortality and morbidity. Millbank $Q$ 1987;65:129-199.

19 Rosenfeld S. A divided South. Southern Exposure 1983;14 10-17.

20 Rosenfeld SA, Bergmar EM, Rubin S. After the factories: changing employment patterns in the rural South. Research Triangle Park, NC: Southern Growth Policies Board, 1985 .

21 James DR. The transformation of the southern racial state: class and race determinants of local state structures. Amer ican Social Reviews 1988;53:191-208.

22 International classification of disease. 8th Rev, adapted for use in the United States. Vol I. DHEW PHS Publication No $1696,1969$.
23 International classification of diseases. Manual of the international statistical classification of diseases, injuries, and causes of death. Based on the recommendations of the 9th revision conference, 1975, and adapted by the 29th World Health Assembly. Vol I. 1977.

24 Sempos C, Cooper R, Kovar MG, McMillen M. Divergence of the recent trends in coronary mortality for the four major race-sex groups in the United States. Am $\mathcal{F}$ Public major race-sex groups in the
Health 1988;78(11):1422-27.

25 Ingram DD, Gillum RF. Regional and urbanization differentials in coronary heart disease mortality in the Unite States, 1968-85. F Clin Epidemiol 1989;42(9):857-868.

26 Human Resources Administration. The area resource file: a health professional's planning and research tool. Washington DC: DHHS Publication no (HRA) 81-9.

27 Bureau of the Census. 1960 census of population. Vol I Characteristics of population, chapter C. Washington DC: US Government Printing Office, 1963.

28 Bureau of the Census. 1970 census of population. Vol II Characteristics of population, chapter C. Washington DS: Characteristics of population, chapter C.

29 Bureau of the Census. 1980 census of population. Vol Characteristics of population, chapter C. Washington DC US Government Printing Office, 1983.

30 US Bureau of the Census. Statistical abstract of the United States: 1969. Washington, DC: US Government Printing Office, 1969.

31 US Bureau of the Census. Statistical abstract of the United States: 1984. 104th ed. Washington: US Government Printing Office.

32 Marmot MG, Adelstein AM, Robinson N, Rose GA. Changing social distribution of heart disease. BMF 1978;ii:110912 .

33 Wing $\mathrm{S}$. Social inequalities in the decline of coronary mortality. Am ₹ Public Health 1988;78:1415-16.

34 Fusfield DR, Bates T. The political economy of the urban ghetto. Carbondale: University of Illinois Press, 1984.

35 Stevens J, Keil JE, Rust PF, Tyroler HA, Davis CE, Gaze PC. Body mass index and body girths as predictors of mortality in black and white women. Arch Intern Med 1992;152:1257-62.

36 Tyroler HA, Knowles MG, Wing SB, Logue EE, Davis CE Heiss G, Heyden S, Hames CG. Ischemic heart disease risk factors and twenty-year mortality in middle-age Evan County black males. Am Heart $\mathcal{f} 1984 ; 108: 738$

37 Stevens J, Keil JE, Rust PF, Verdugo RR, Davis CE, Tyrole HA, Gazes PC. Body mass index and body girths as predictors of mortality in black and white men. $A m \mathcal{f}$ Epidemiol 1992;135:1137-46.

38 Johnson JL, Heineman EF, Heiss G, Hames CG, Tyroler HA. Cardiovascular disease risk factors and mortality among black women and white women aged 40-64 years in Evans County, Georgia. Am f Epidemiol 1986;123: in Evans

39 Casper ML. Antihypertensive treatment and US trends in stroke mortality, 1962-1980. Ann Arbor, Michigan: UM Dissertation Service; 1991. (Dissertation).

40 James SA, Hartnett SA, Kalsbeek WD. John Henryism and blood pressure differences among black men. 7 Behav Med 1983;6(3):259-78.

41 Harburg E, Erfurt JC, Chape C, Hauenstein LS, Schull WJ, Schork MA. Socioecological stressor areas and blackwhite blood pressure: Detroit. $f$ Chronic Dis 1973;26: 595-611.

42 Harburg E, Erfurt JC, Hauenstein LS, Chape C, Schull WJ, Schork MA. Suppressed hostility, skin color, and blackwhite blood pressure: Detroit. Psychosom Med 1973;35(4) 276-96.

43 Landsbergis PA, Schurman SJ, Israel BA, Schnall PL, Hugentobler MK, Cahill J, Baker D. Job stress and hear disease: evidence and strategies for prevention. New Solutions 1993;3:42-58.

44 Cobb JC. Industrialization and southern society. Lexington KY: The University Press of Kentucky, 1984.

45 Ford AM. Political economies of rural poverty in the South. Cambridge, MA: Ballinger Publishing Co. 1973

46 Seigal JS. Estimates of coverage of the population by sex race, and age in the 1970 census. Demography 1974;11: $1-23$.

47 US Bureau of the Census. Current population reports. Series P-23, no 115, Coverage of the national population in the 1980 census, by age, sex, and race: preliminary estimates by demographic analysis. Washington DC: US Government Printing Office, 1982.

48 Gittlesohn A, Royston P. Annotated bibliography of cause of death validation studies 1958-1980. Vital and Health Statistics, Series 2, No 89. DHHS Publication No (PHS) 82-1363, 1982.

49 Gittlesohn A, Senning J. Studies on the reliability of vital and health records: I. Comparison of cause of death and hospital record diagnoses. Am F Public Health 1979;69: 680-9.

50 Armstrong D, Wing S, Tyroler HA. US mortality from illdefined causes, 1968-1988: potential effects on heart
disease mortality trends. Int $\mathcal{F}$ Epidemiol 1995;24(3):522-7.

51 Barnett E, Casper M. Recent trends in coronary heart diseas and stroke mortality among adults, North Carolina, 1980 and stroke mortality among adults, North Carolina, 1980Statistics, no 98, 1995. 